\title{
GDP Development of China and USA in terms of mutual sanctions and COVID-19
}

\author{
Petr Šuleř ${ }^{1, *}$, and Jaromír Vrbka ${ }^{1}$ \\ ${ }^{1}$ Institute of Technology and Business in Ceske Budejovice, School of Expertness and Valuation, \\ Okruzní 517/10, 37001 Ceske Budejovice, Czech Republic
}

\begin{abstract}
.
Research background: China's share in the global economy has experienced a swift growth since opening up and reforming the country's foreign policy in 1978. USA sanction on China has so far concentrated on a heap of issues including China's enormous exchange shortfall with the U.S., currency control, constrained market access, licensed innovation robbery and security issues identified with Huawei. Also, USA sanction on China has so far lead to a decrease in exports and outflow of FDI, reduce in the inflow trade and investment, and apparently hinders the Chinese GPD growth and diminished its currency exchange rate.

Purpose of the article: The aim is to predict the future development of the GDP of the China and the USA and to estimate their further development through the prism of mutual trade sanctions and COVID-19.

Methods: The data collection demonstrates the course of a time series of a daily RMB exchange rate development from the beginning of 1992 to June 2020. Furthermore, it represents the time series of a quarterly development of the Chinese GDP for the same time period. Using neural networks, a regression for different variants of the time series delay in connection with the analysis of the USA sanctions is conducted.

Findings \& Value added: The GDP of both countries has developed over the last two years, as if sanctions had not been imposed. However, the situation is changing with COVID-19. In this case, it is clear that the impact will be more significant. US GDP will stagnate. PRC GDP will fall.
\end{abstract}

Keywords: People's Republic of China; GDP; RMB exchange rate; sanctions; machine learning

JEL Classification: $C 45 ; E 01 ; F 31$

\section{Introduction}

China's share in the global economy has experienced a swift growth since opening up and reforming the country's foreign policy in 1978. The quality of the life of the Chinese has

${ }^{*}$ Corresponding author: vrbka@mail.vstecb.cz 
upgraded dramatically base on GDP standards [1]. However, the country's statistics is believed to be faulty and altered from actual data on the ground [2]. US sanction on China has so far concentrated on a heap of issues including China's enormous exchange shortfall with the U.S., currency control, constrained market access, licensed innovation robbery and security issues identified with Huawei.

Also, US sanction on China has so far lead to a decrease in exports and outflow of FDI, reduce in the inflow trade and investment, and apparently hinders the Chinese GPD growth and diminished its currency exchange rate [3].

This paper primarily focusses on China's GDP growth rate in the context of US sanctions and COVID-19 situation.

\section{Literary Research}

Liang [4] believed that transforming industrial structures and economic growth are reliant and reciprocally reinforcing, and a change in those structures are the basis of the Chinese economic growth. The researcher established a multiple linear regression model, and concludes the importance of industrial structure adjustment promotes the sustainable development of China's economy. China's financial markets is center around directing its capital to state-owned enterprises. Economic development and the related idea of GDP are reliant, to a limited extent, on the achievement of financial division rebuilding. Economic advancement procedures and the results of such techniques are never decided exclusively by nearby conditions however are resolute by changing worldwide conditions [5].

Ji [6] find an uneven distribution in one of China's province GDP growth rate and revealed that local officials preciously effect statistical data in order to exceed thresholds, but do not unescapably imply data distortion. Urbanization, economic development, and changes in arboreal areas have shown a clear relationship between forest cover and per capita GDP [7]. According to Zheng and Walsh [8] China's advancement has been portrayed by elevated level of substantial industry, worldwide trade exchange and urbanization progress. Investigations have shown that urbanization and wealth are the significant supports for China's economic development. Changing the business and exchange structure financial development is the need for the arrangement producers. In most of the major cities in China, non-agricultural population share, gross industrial and foreign investment in actual use are top socioeconomic factors influencing urban growth [9]. Mikheev and Lukonin [10] believed that the effect of US sanction on Chinese economy remains reasonably negative. However, the development potential of the country may endure considerable calamities if the US keep on keeping up thrilling measures. However, Li [11] proposed that in 2026, China's GDP would exceed the United States GDP, thus anticipated GDP will be 2.22 times higher than the US by 2050. Liu et al. [12] recently, China's trade struggle with the United States has increased worries on the economic advancement, harmonization, and rebuilding from Tradeled GDP growth approach to one impelled by domestic consumption. The researchers discover proof demonstrating increased significance of exports in China's GDP development after the Global financial crisis, and their outcomes propose that the progress from a tariff drove development methodology is continuing far less easily than trusted [13]. The go head to head has so far concentrated on a heap of issues including China's enormous trade shortage with the United States, currency manipulation, constrained market access, protected innovation robbery and security issues identified with Huawei.

Researchers like Rawski [14], Holz [15], and Kerola [16] alleged that Chinese statistics contain major exaggerations of real output growth are controversial and is below official figures. Whereas, in other developing countries especially in Sub-Saharan Africa actual GDP growth rate is more than official data [17]. 
The researcher aims to analyzing the development of China's GDP growth and currency exchange rate with the view of US sanctions. On one hand, it can be concluded that the Chinese authorities devalue the RMB to its most minimal level in decades against the US dollar and could proceed for a long time in the midst of the clear move in strategic position by the officials, who are demonstrating expanding hesitance to give concessions to determine its trade war with the United States. On the other hand, China's GDP growth rate is not the same on the ground as reported by the People's Bank of China. This assumption is inline with that put forward by many researchers from the review. Also, due to US ban on leading technology companies, tariffs on exported goods to the US, and human right concerns in the Xingjiang province, the country has experienced a worsening funding conditions for Chinese companies, and negative effect on gross capital inflow.

\section{Data and Methods}

The aim is to predict the future development of the GDP of the People's Republic of China (hereinafter referred to as the PRC) and the United States of America (hereinafter referred to as the USA) and to estimate their further development through the prism of mutual trade sanctions and COVID-19. In accordance with the aim of the paper, we determine two research questions:

1. Which of the analysed countries' GDP were more significantly affected by sanctions?

2. Which country's GDP will be significantly affected in the future by COVID-19 sanctions and the pandemic?

The text is based on publicly available information. Data on Chinese GDP comes from the website http://data.stats.gov.cn/english/easyquery.htm?cn=B01. The information on the website is given in 100 million RMB. The information on Chinese GDP had to be converted to the same monetary unit as in the case of US GDP, i.e. billions of USD. The PRC GDP values were converted using the USD / RMB exchange rate valid on the last day of the given calendar month to which the GDP data refer. The USD / RMB exchange rate is available on the website. US GDP data is available on the website https://fred.stlouisfed.org/series/GDP. This piece of data is presented directly in billions of USD. Data on the PRC GDP were validated from the same source. Quarterly data on the development of Chinese GDP and US GDP for the period from the beginning of 1992 to the first quarter of 2020 were used.

The data was divided by the method of random selection into three sets - a training set used to create a prediction model; a testing set used to verify the correctness of the generated model; and a validation set serving to verify the correctness of the created model for the second time. The training data set will contain $70 \%$ of the input data, the testing and validation set will always contain $15 \%$ of the data. Ideally, the basic statistics of the data subfiles differ. This will provide a better possibility to check the accuracy of the created prediction model. Distribution data into training, test and validation data sets is important for model validation. The accuracy of each modeling and time series prediction should be verified and therefore used this division.

The prediction model will be created for each time series separately. TIBCO's Statistica software in version 13 will be used. Specifically, the Data Mining, Neural Networks module will be used. Automated neural networks (ANN) will be used. We will work with time series regression. The input variables will always be represented by the respective year and quarter. In both cases, we will always work with a continuous variable which is expressed by an integer. The dependent, i.e. target, variable will result from the value of the respective GDP. In both cases, 100,000 neural structures will be generated. Using the iteration of the scales, the neural network with the most accurate results in the time series balancing will be identified. We work with the assumption that the further development of the time series will follow approximately the same model as before. Using the method of analogy, we will 
estimate the development of the balanced time series. Models will be created using two types of neural networks. The first of them is the basic type of neural networks - specifically, it will be a multilayer (or in this case three-layer) neural network (MLP). The second type of neural network used will be the radial basic function (RBF) neural network. This kind of works with the fuzzy logic. To activate the hidden and output MLP layer, the following functions will be used: exponential, hyperbolic tangent, exponential function, logistic function, identical function and sine function. Activation functions introduce an element of nonlinearity into the neural network. In the hidden layer of neurons, we will work with the number of 2 to 12 neurons. For RBF networks, we will work with 21 to 31 hidden neurons.

In the case of both time series, we will count on a delay of 4 quarters, i.e. one year. This means that each additional value will be derived from the values of the previous four quarters. This will prevent extreme fluctuations of the balanced time series. On the other hand, however, it may happen that the balanced time series does not completely cover the possible real extreme of the development of the observed variable. From the generated neural structures, we always keep the five most successful for each time series. These will be the networks with the best performance parameters for all subsets of data and, simultaneously, with the lowest error occurrence. Subsequently, we perform an analysis and a prediction using all preserved neural networks. This will determine not only whether neural networks are able to balance the time series, but also whether they suffer from overfitting. This is characterized by the fact that the balanced time series show excellent performance parameters, but they compensate the time series meaninglessly, or they are unusable in predicting the future development of the time series. Once the best model is always selected, the future development of both time series, i.e. the PRC GDP and US GDP, will be expertly analysed.

\section{Results}

\subsection{PRC GDP}

An overview of generated and preserved neural networks for PRC GDP prediction is given in Table 1.

Table 1. Overview of preserved neural networks for the PRC GDP prediction.

\begin{tabular}{|c|c|c|c|c|c|c|c|c|c|c|c|}
\hline Index & $\begin{array}{c}\text { Net. } \\
\text { name }\end{array}$ & $\begin{array}{c}\text { Training } \\
\text { perf. }\end{array}$ & Test perf. & $\begin{array}{c}\text { Validation } \\
\text { perf. }\end{array}$ & $\begin{array}{c}\text { Training } \\
\text { error }\end{array}$ & $\begin{array}{c}\text { Test } \\
\text { error }\end{array}$ & $\begin{array}{c}\text { Validation } \\
\text { error }\end{array}$ & $\begin{array}{c}\text { Training } \\
\text { agorithm }\end{array}$ & $\begin{array}{c}\text { Error } \\
\text { function }\end{array}$ & $\begin{array}{c}\text { Hidden } \\
\text { activation }\end{array}$ & $\begin{array}{c}\text { Output } \\
\text { activation }\end{array}$ \\
\hline 1 & $\begin{array}{c}\text { MLP } \\
8-5-1\end{array}$ & 0.996501 & 0.987422 & 0.999373 & 4210.896 & 1459.736 & 1310.935 & BFGS 54 & SOS & Logistic & Sine \\
\hline 2 & $\begin{array}{c}\text { MLP } \\
8-3-1\end{array}$ & 0.995555 & 0.986666 & 0.999445 & 5373.042 & 3863.919 & 1018.403 & BFGS 57 & SOS & Tanh & Tanh \\
\hline 3 & $\begin{array}{l}\text { MLP } \\
8-9-1\end{array}$ & 0.995946 & 0.986889 & 0.999404 & 4901.675 & 2903.729 & 1469.743 & BFGS 147 & SOS & Exponential & Logistic \\
\hline 4 & $\begin{array}{l}\text { MLP } \\
8-5-1\end{array}$ & 0.996182 & 0.987276 & 0.999444 & 4607.919 & 2426.086 & 1377.464 & BFGS 56 & SOS & Logistic & Tanh \\
\hline 5 & $\begin{array}{l}\text { MLP } \\
8-7-1\end{array}$ & 0.996045 & 0.986948 & 0.999372 & 4779.773 & 2719.594 & 1402.253 & BFGS 91 & SOS & Exponential & Logistic \\
\hline
\end{tabular}

Source: Own source.

The table shows that all preserved neural networks show a very high performance in balancing the time series. The network performance measured by the correlation coefficient is greater than 0.99 for the training data set in the case of all networks, always higher than 0.98 for the testing data set and again higher than 0.99 for the validation data set. With regard to the number of samples, the calculated error of all networks appears to be minimal. In all 
cases, these are MLP networks that use 3 to 9 neurons in the hidden layer. All were created using the Search Results function. The search results were obtained from the Broyden Fletcher - Goldfarb - Shanno algorithm (BFGS) website. The least squares method was used as an error function. To activate the hidden layer of neurons, neural networks use the exponential function, the logistic function and the hyperbolic tangent. The output neuron is then activated via a logistic function, a hyperbolic tangent, and a sine function.

However, based on the above, it is not possible to identify the most successful neural network. They all need a further analysis. Table 2 contains basic statistics of balanced time series according to sub-sets of input information.

Table 2. Basic statistics of balanced time series according to sub-sets of input information.

\begin{tabular}{|c|c|c|c|c|c|}
\hline Statistics & $\begin{array}{c}\text { 1.MLP } \\
8-5-1 \\
\end{array}$ & $\begin{array}{c}\text { 2.MLP } \\
\text { 8-3-1 }\end{array}$ & $\begin{array}{c}\text { 3.MLP } \\
\text { 8-9-1 }\end{array}$ & $\begin{array}{c}\text { 4.MLP } \\
8-5-1\end{array}$ & \begin{tabular}{|c|} 
5.MLP \\
$8-7-1$ \\
\end{tabular} \\
\hline Minimum prediction (Train) & 84.152 & 91.499 & 155.560 & 64.144 & 190.133 \\
\hline Maximum prediction (Train) & $3,780.133$ & $3,591.475$ & $3,648.241$ & $3,682.103$ & $3,656.287$ \\
\hline Minimum prediction (Test) & 134.251 & 98.683 & 151.766 & 106.363 & 194.446 \\
\hline Maximum prediction (Test) & $3,663.865$ & $3,492.306$ & $3,555.421$ & $3,585.532$ & $3,565.166$ \\
\hline Minimum prediction (Validation) & 134.156 & 150.519 & 165.433 & 136.894 & 191.064 \\
\hline Maximum prediction (Validation) & $3,507.552$ & $3,483.504$ & $3,446.588$ & $3,467.217$ & $3,476.077$ \\
\hline Minimum residual (Train) & -339.919 & -446.107 & -350.931 & -365.752 & -344.173 \\
\hline Maximum residual (Train) & 270.354 & 401.167 & 344.402 & 310.540 & 336.355 \\
\hline Minimum residual (Test) & -52.169 & -107.591 & -83.915 & -60.576 & -86.902 \\
\hline Maximum residual (Test) & 134.830 & 270.272 & 207.157 & 177.046 & 197.411 \\
\hline Minimum residual (Validation) & -85.923 & -84.315 & -70.148 & -108.550 & -83.675 \\
\hline Maximum residual (Validation) & 137.951 & 51.477 & 118.606 & 113.276 & 125.299 \\
\hline Minimum standard residual (Train) & -5.238 & -6.086 & -5.012 & -5.388 & -4.978 \\
\hline Maximum standard residual (Train) & 4.166 & 5.473 & 4.919 & 4.575 & 4.865 \\
\hline Minimum standard residual (Test) & -1.365 & -1.731 & -1.557 & -1.230 & -1.666 \\
\hline Maximum standard residual (Test) & 3.529 & 4.348 & 3.844 & 3.594 & 3.785 \\
\hline Minimum standard residual (Validation) & -2.373 & -2.642 & -1.830 & -2.925 & -2.235 \\
\hline Maximum standard residual (Validation) & 3.810 & 1.613 & 3.094 & 3.052 & 3.346 \\
\hline
\end{tabular}

Source: Own source.

Ideally, we expect data close to the values given in Table 2. Furthermore, we expect minimum residue values. Most balanced time series statistics are close to each other. The exception is the minimum of balanced time series. The closest values of all neural networks were found in the neural network 2. MLP 8-3-1. Graphically, the course of the balanced time series and the actual course of the PRC GDP is shown in Figure 1. 


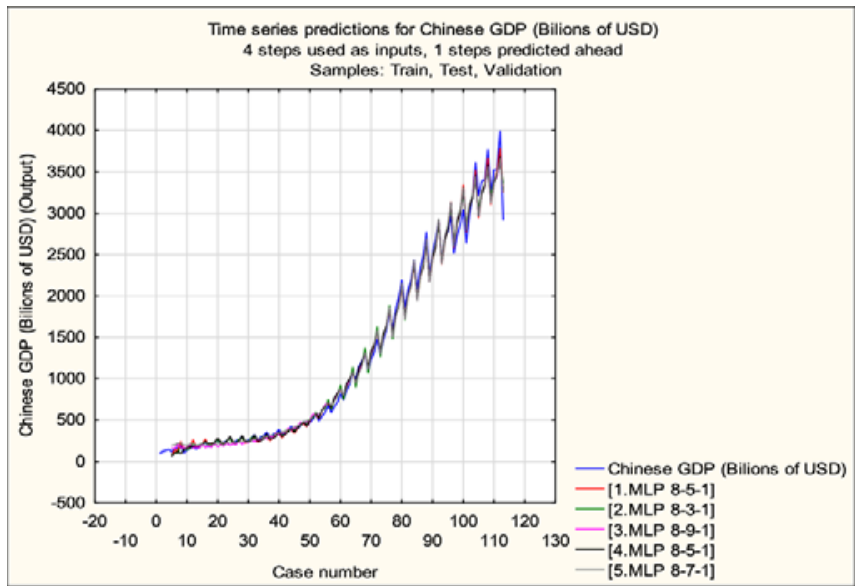

Fig. 1. Balanced time series and the actual course of PRC GDP. Source: Own source.

Once more, the figure confirms that all neural networks balance the course of the PRC GDP very successfully. However, based on the performed analysis, we can state that the network 2. MLP 8-3-1 appears to be slightly more accurate. The prediction of PRC GDP until the end of the year 2021 is illustrated below, in the graph in Figure 2.

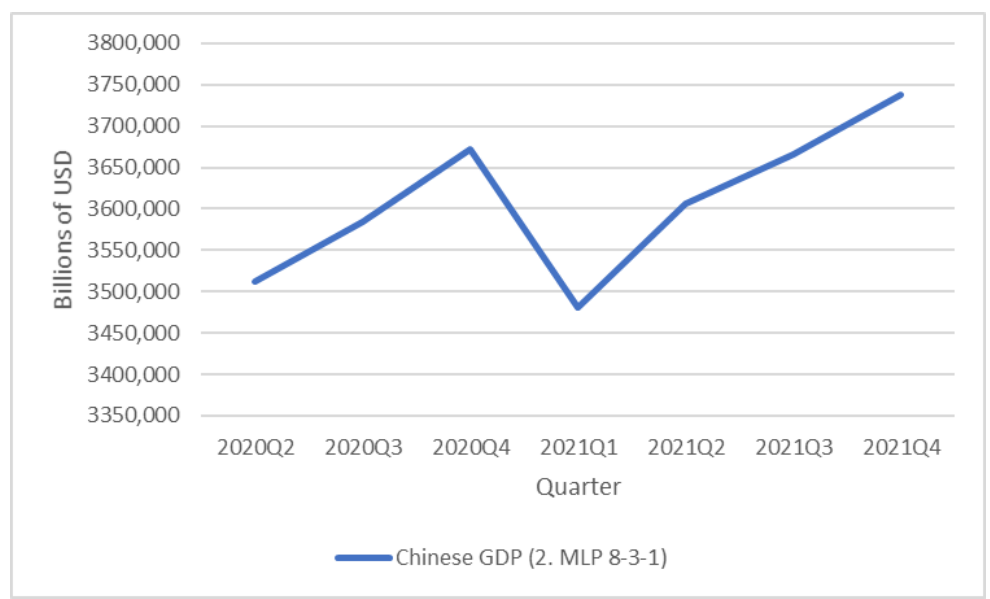

Fig. 2. Prediction of PRC GDP until the end of the year 2021. Source: Own source.

\subsection{US GDP}

The preserved neural networks most successfully balancing the US GDP time series are the subject of Table 3 . 
Table 3. Overview of preserved neural networks for the prediction of US GDP.

\begin{tabular}{|c|c|c|c|c|c|c|c|c|c|c|c|}
\hline Index & $\begin{array}{c}\text { Net. } \\
\text { name }\end{array}$ & $\begin{array}{c}\text { Training } \\
\text { perf. }\end{array}$ & $\begin{array}{c}\text { Test } \\
\text { perf. }\end{array}$ & $\begin{array}{c}\text { Validation } \\
\text { perf. }\end{array}$ & $\begin{array}{c}\text { Training } \\
\text { error }\end{array}$ & $\begin{array}{c}\text { Test } \\
\text { error }\end{array}$ & $\begin{array}{c}\text { Validation } \\
\text { error }\end{array}$ & $\begin{array}{c}\text { Training } \\
\text { algorithm }\end{array}$ & $\begin{array}{c}\text { Error } \\
\text { function }\end{array}$ & $\begin{array}{c}\text { Hidden } \\
\text { activation }\end{array}$ & $\begin{array}{c}\text { Output } \\
\text { activation }\end{array}$ \\
\hline 1 & $\begin{array}{c}\text { MLP } \\
8-8-1\end{array}$ & 0.999544 & 0.962027 & 0.999823 & 4246.083 & 4884.139 & 9843.060 & BFGS 241 & SOS & Tanh & Identity \\
\hline 2 & $\begin{array}{c}\text { MLP } \\
8-9-1\end{array}$ & 0.999475 & 0.962071 & 0.999769 & 5429.393 & 3236.923 & 4885.926 & BFGS 149 & SOS & Tanh & Logistic \\
\hline 3 & $\begin{array}{c}\text { MLP } \\
8-6-1\end{array}$ & 0.999642 & 0.962137 & 0.999842 & 2579.174 & 1794.214 & 7141.410 & BFGS 229 & SOS & Tanh & Tanh \\
\hline 4 & $\begin{array}{c}\text { MLP } \\
8-7-1\end{array}$ & 0.999406 & 0.962123 & 0.999760 & 6619.686 & 2555.108 & 4966.307 & BFGS 231 & SOS & Tanh & Logistic \\
\hline 5 & $\begin{array}{c}\text { MLP } \\
8-6-1\end{array}$ & 0.999386 & 0.962052 & 0.999856 & 6965.119 & 3319.179 & 3054.822 & BFGS 137 & SOS & Logistic & Tanh \\
\hline
\end{tabular}

Source: Own source.

Even in this case, it can be stated that neural networks are very successful. In the training data set, they all have a correlation coefficient value higher than 0.99 . In the testing data set created by the BFGS algorithm, the neural networks show an error higher than the networks balancing the PRC's GDP, but still on an acceptable level. The least squares method was again chosen to calculate the error. Neural networks use hyperbolic tangent and logistic function to activate the hidden layer of neurons. The logistic, identical and hyperbolic tangent functions are used to activate the output layer.

Based on the parameters of the overview table, it is not possible to select the most successful neural network. Table 4 offers basic statistics of balanced time series.

Table 4. Basic statistics of balanced time series according to sub-sets of input information.

\begin{tabular}{|c|c|c|c|c|c|}
\hline Statistics & $\begin{array}{c}\mathbf{1 . M L P} \\
\mathbf{8 - 8 - 1}\end{array}$ & $\begin{array}{c}\mathbf{2 . M L P} \\
\mathbf{8 - 9 - 1}\end{array}$ & $\begin{array}{c}\mathbf{3 . M L P} \\
\mathbf{8 - 6 - 1}\end{array}$ & $\begin{array}{c}\text { 4.MLP } \\
\mathbf{8 - 7 - 1}\end{array}$ & $\begin{array}{c}\mathbf{5 . M L P} \\
\mathbf{8 - 6 - 1}\end{array}$ \\
\hline Minimum prediction (Train) & $6,841.45$ & $6,651.10$ & $6,780.30$ & $6,858.93$ & $6,835.86$ \\
\hline Maximum prediction (Train) & $21,670.63$ & $21,624.71$ & $21,564.22$ & $21,667.01$ & $21,633.48$ \\
\hline Minimum prediction (Test) & $6,853.07$ & $6,716.40$ & $6,860.58$ & $6,914.87$ & $7,004.24$ \\
\hline Maximum prediction (Test) & $21,150.74$ & $21,365.45$ & $21,267.01$ & $21,386.20$ & $21,360.02$ \\
\hline Minimum prediction (Validation) & $7,123.17$ & $7,185.76$ & $7,105.79$ & $7,096.70$ & $7,072.40$ \\
\hline Maximum prediction (Validation) & $21,302.25$ & $21,470.79$ & $21,348.77$ & $21,502.44$ & $21,448.57$ \\
\hline Minimum residual (Train) & -190.26 & -393.03 & -148.11 & -405.88 & -450.52 \\
\hline Maximum residual (Train) & 199.40 & 224.85 & 261.71 & 260.07 & 211.85 \\
\hline Minimum residual (Test) & -132.15 & -176.08 & -80.21 & -140.49 & -195.30 \\
\hline Maximum residual (Test) & 192.64 & 124.98 & 157.75 & 130.18 & 191.17 \\
\hline Minimum residual (Validation) & -134.01 & -198.85 & -142.26 & -178.81 & -176.98 \\
\hline Maximum residual (Validation) & 270.40 & 133.69 & 257.84 & 138.70 & 114.75 \\
\hline Minimum standard residual (Train) & -2.92 & -5.33 & -2.92 & -4.99 & -5.40 \\
\hline Maximum standard residual (Train) & 3.06 & 3.05 & 5.15 & 3.20 & 2.54 \\
\hline
\end{tabular}




\begin{tabular}{|c|c|c|c|c|c|}
\hline Minimum standard residual (Test) & -1.89 & -3.09 & -1.89 & -2.78 & -3.39 \\
\hline Maximum standard residual (Test) & 2.76 & 2.20 & 3.72 & 2.58 & 3.32 \\
\hline Minimum standard residual (Validation) & -1.35 & -2.84 & -1.68 & -2.54 & -3.20 \\
\hline Maximum standard residual (Validation) & 2.73 & 1.91 & 3.05 & 1.97 & 2.08 \\
\hline
\end{tabular}

Source: Own source.

Here, too, we are looking for minima and maxima similar to the data in Table Two and minimum residue values, i.e. minima and maxima approaching zero. Networks are very similar in their characteristics. Nevertheless, the 2. MLP 8-9-1 appears to be almost imperceptibly the best neural network.

The graphic course of balanced time series and the actual development of US GDP is the subject of Figure 3.

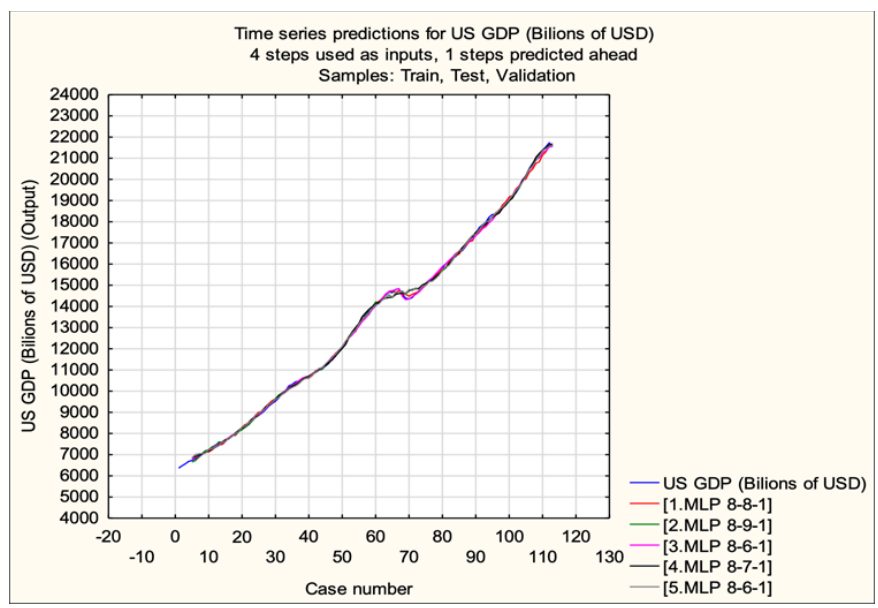

Fig. 3. Balanced time series and the actual development of US GDP. Source: Own source.

Even in this case, it is confirmed that all neural networks are very successful in balancing the US GDP time series. Due to the fact that the 2. MLP 8-9-1 shows slightly better results than other networks, we will continue to work only with this model. The forecast until the end of the year 2021 is the subject of Figure 4.

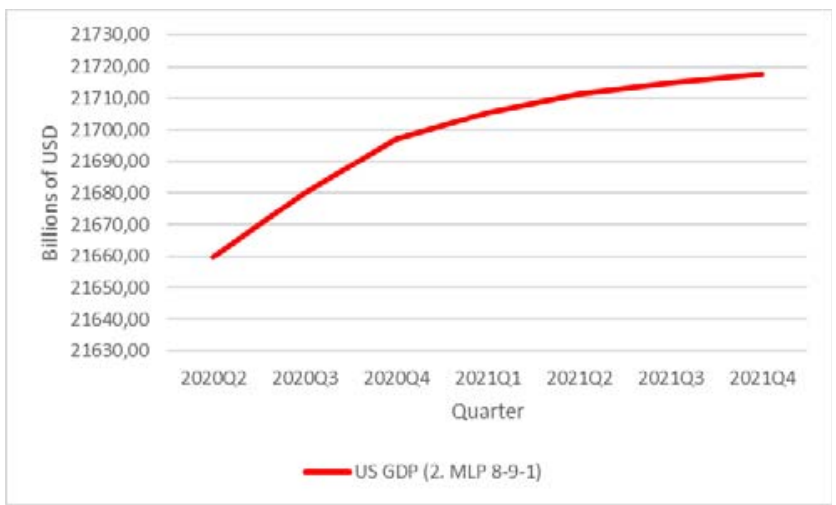

Fig. 4. Prediction of US GDP until the end of the year 2021. Source: Own source. 
Based on the performed analysis, the prediction of the development of the PRC GDP and US GDP until the end of 2021 was calculated. The current course of development of both variables and at the same time the prediction is offered in Figure 5.

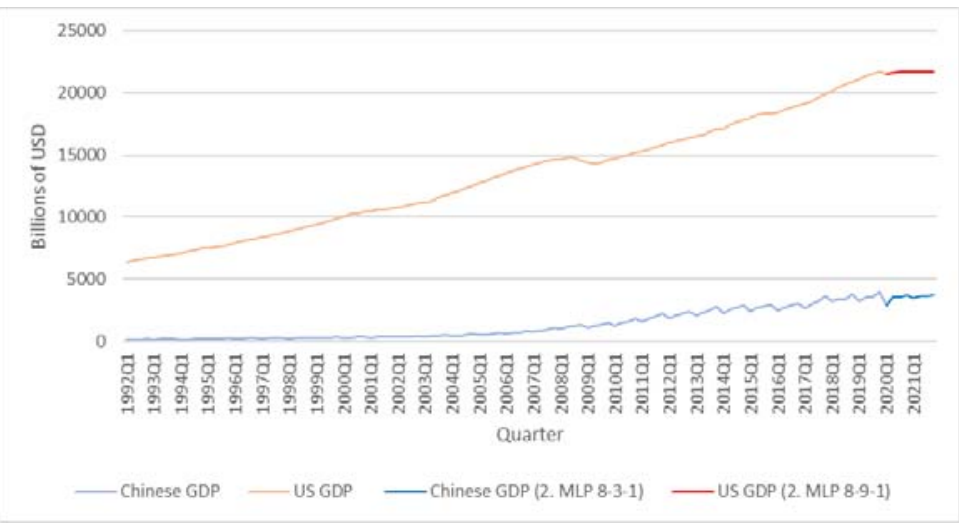

Fig. 5. Prediction of the development of PRC GDP and US GDP until the end of the year 2021. Source: Own source.

In the process of answering the research question, two issues were identified. First, we are concerned with the question which one of the two countries and its GDP is affected by the current sanctions (or trade war) more. The picture shows that the sanctions have a more significant impact on the GDP of the PRC. The GDP of both countries develops very differently over time. PRC GDP is subject to seasonal fluctuations over time. It is always possible to observe the lowest performance of the Chinese economy in the first quarter of the year. This is followed by a growth until the end of the fourth quarter. Subsequently, this is followed by a fall between the fourth quarter of last year and the first quarter of the current year. Therefore, the question is whether the fluctuation in the first quarter of 2020 was only a seasonal fluctuation, or whether it is affected by sanctions or measures against COVID-19. From the graph in Figure 6, it is possible to deduce a significantly larger fluctuation than just the effect of the season. It should be noted that, on a scale, this is a decrease of about $25 \%$. However, this phenomenon is not followed by an increase as in was the case in the previous periods. The minimal growth and subsequent stabilization below the level of the last more than two years indicates the PRC government's efforts to respond to the effects of the spread of COVID-19.

It can be stated that the development of US GDP in the past was not subject to seasonal fluctuations and grew steadily throughout the time. In addition, in absolute terms, the US GDP grew faster than in the PRC. In the last quarter observed, there was a slight decline in form of a couple of percentage units. Artificial intelligence responds to this by predicting stagnation until 2021. It predicts that the US economy is coping very well with Chinese sanctions, as it has been growing steadily since their introduction. However, it responds to the development of COVID-19 by stagnation. Nevertheless, unlike the Chinese economy, it is not declining. It can be concluded that this is due to at least two reasons. The first reason can be seen in the fact that the USA was affected by COVID-19 only after Asia and Europe. They were able to prepare at the macroeconomic level (despite the fact that in the first weeks and months, the US President did not perceive the contagion as a real threat). Overall, companies with American roots are very flexible and make decisions relatively quickly, in contrast to the PRC, especially in terms of human resource management. We can therefore conclude that:

1. The US has not been harmed by mutual sanctions with the PRC. 
2. The PRC has been harmed by mutual sanctions with the USA. However, it was able to react and find a suitable market for its goods in a relatively short time.

3. The US was damaged by COVID-19. The situation will certainly stagnate its GDP by the end of 2021 .

4. The PRC was damaged by COVID-19. Measures against the disease will cause a decline in the performance of the Chinese economy at least until the end of 2021.

The analysis carried out in order to answer the first research question also shows the answer to the second question. The development of the GDP of both countries shows that the performance of the PRC will be more significantly affected than the US GDP. In the first case, there will be a decline in economic performance, in the second case only a stagnation. In addition to that, the rule of large numbers certainly applies. If the same percentage decline in US GDP as the PRC GDP were predicted, the impact on the US economy would be more modest.

\section{Conclusion}

The aim of the paper was to predict the future development of GDP of PRC and the USA and to estimate their further development through the prism of mutual trade sanctions and COVID-19.

In order to fulfil the set goal, we identified two research questions. From the answers to these questions, it is clear that both economies have managed to cope with mutual sanctions. However, it is recalled that this was a difficult task, especially for the PRC. However, the GDP of both countries has developed over the last two years, as if sanctions had not been imposed. However, the situation is changing with COVID-19. In this case, it is clear that the impact will be more significant. US GDP will stagnate. PRC GDP will fall. Neither of the two countries will deal with the effects of the spread of COVID-19 by the end of 2021, i.e. the countries cannot reverse the negative development or zero growth.

The paper does not take a possible second wave of COVID-19 pandemics into account, provided it had the dimensions of the first wave. However, it can be assumed that even if the disease strikes again at the same rate as in the first wave, the measures will not be the same. The governments of all countries have learned from the development so far and the measures affecting the economy would not be so strong. In addition, citizens of the respective countries start to react negatively to measures against COVID-19. The effort to apply such far-reaching measures is minimal. In future research, it would be very interesting to examine the declines in trade on the world markets (trade gaps).

\section{References}

1. He, Y., Sheng, P., Vochozka, M. (2017). Pollution caused by finance and the relative policy analysis in China. Energy \& Environment, 28(7), 808-823.

2. Vrbka, J., Šuleř, P., Machová, V., Horák, J. (2019). Considering seasonal fluctuations in equalizing time series by means of artificial neural networks for predicting development of USA and People's Republic of China trade balance. Littera Scripta, 12(2), 178-193.

3. Machová, V., Mareček J. (2019). Estimation of the development of Czech Koruna to Chinese Yuan exchange rate using artificial neural networks. In J. Horák (Ed.), SHS Web of Conferences: Innovative Economic Symposium 2018 - Milestones and Trends of World Economy (IES2018). Les Ulis, France: EDP Sciences.

4. Liang, X. (2019). Study on the impact of industrial structure on GDP and economic growth in China based on multiple regression. In C. Huang, Y. Zhong \& Z. Wang (Eds.), 
Proceedings of the 4th International Conference on Financial Innovation and Economic Development (ICFIED 2019) (pp. 350-354). Paris, France: Atlantis Press.

5. Hašková, S., Volf, P., Machová, V. (2019). Economic convergence of Czech regions in terms of GDP and unemployment rate in response to FDI flows: Do businesses and regions flourish? Ad Alta: Journal of Interdisciplinary Research, 9(1), 326-329.

6. Ji, D. (2019). Unusual patterns in China's prefectural GDP growth rates. Applied Economics Letters, 26(4), 331-334.

7. Wang, J., Xin, L., Wang, Y. (2019). Economic growth, government policies, and forest transition in China. Regional Environmental Change, 19(4), 1023-1033.

8. Zheng, W., Walsh, P. P. (2019). Economic growth, urbanization and energy consumption - A provincial level analysis of China. Energy Economics, 80, 153-162.

9. Li, C., Li, J., Wu, J. (2018). What drives urban growth in China? A multi-scale comparative analysis. Applied Geography, 98, 43-51.

10. Mikheev, V. V., Lukonin, S. A. (2019). New stage in China's development amid the" trade war" with the U.S. Mirovaya Ekonomika i Mezhdunarodnye Otnosheniya, 63(2), 56-65.

11. Li, C. (2018). China's 2009-2050 economic growth: A new projection using the Marxian optimal growth model. World Review of Political Economy, 9(4), 429-450.

12. Liu, M. H., Margaritis, D., Zhang, Y. (2019). The global financial crisis and the exportled economic growth in China. The Chinese Economy, 52(3), 232-248.

13. Rowland, Z., Šuleř, P., Vochozka, M. (2019). Comparison of neural networks and regression time series in estimating the Czech Republic and China trade balance. In J. Horák (Ed.), SHS Web of Conferences: Innovative Economic Symposium 2018 Milestones and Trends of World Economy (IES2018). Les Ulis, France: EDP Sciences.

14. Rawski, T. G. (2001). What is happening to China's GDP statistics? China Economic Review, 12(4), 347-354.

15. Holz, C. A. (2014). The quality of China's GDP statistics. China Economic Review, 30, 309-338.

16. Kerola, E. (2019). In search of fluctuations: Another look at China's incredibly stable GDP growth rates. Comparative Economic Studies, 1-22.

17. Henderson, J. V., Storeygard, A., Weil, D. N. (2012). Measuring economic growth from outer space. American Economic Review, 102(2), 994-1028. 